\title{
Study of Electrical Transport Properties of Thin Films Used as HTL and as Active Layer in Organic Solar Cells, through Impedance Spectroscopy Measurements
}

\author{
Camilo A. Otalora, ${ }^{1}$ Andres F. Loaiza, ${ }^{2}$ and Gerardo Gordillo ${ }^{3}$ \\ ${ }^{1}$ Chemistry Department, Universidad Nacional de Colombia, Bogotá 111321, Colombia \\ ${ }^{2}$ Research Department, Fundación Universidad de América, Bogotá 111711, Colombia \\ ${ }^{3}$ Physics Department, Universidad Nacional de Colombia, Bogotá 111321, Colombia \\ Correspondence should be addressed to Camilo A. Otalora; caotalorab@unal.edu.co
}

Received 14 December 2015; Revised 31 May 2016; Accepted 12 June 2016

Academic Editor: Jamal Berakdar

Copyright (C) 2016 Camilo A. Otalora et al. This is an open access article distributed under the Creative Commons Attribution License, which permits unrestricted use, distribution, and reproduction in any medium, provided the original work is properly cited.

\begin{abstract}
Impedance spectroscopy (IS) is used for studying the electrical transport properties of thin films used in organic solar cells with structure ITO/HTL/active layer/cathode, where PEDOT:PSS (poly(3,4-ethylenedioxythiophene):polystyrene sulfonic acid) and $\mathrm{CuPC}$ (tetrasulfonated copper-phthalocyanine) were investigated as HTL (hole transport layer) and P3HT:PCBM (poly-3hexylthiophene:phenyl-C61-butyric acid methyl ester) blends prepared from mesitylene and chlorobenzene based solutions were studied as active layer and $\mathrm{Ag}$ and $\mathrm{Al}$ were used as cathode. The study allowed determining the influence of the type of solvent used for the preparation of the active layer as well as the speed at which the solvents are removed on the carriers mobility. The effect of exposing the layer of $\mathrm{P} 3 \mathrm{HT}$ to the air on its mobility was also studied. It was established that samples of P3HT and P3HT:PCBM prepared using mesitylene as a solvent have mobility values significantly higher than those prepared from chlorobenzene which is the solvent most frequently used. It was also determined that the mobility of carriers in P3HT films strongly decreases when this sample is exposed to air. In addition, it was found that the electrical properties of P3HT:PCBM thin films can be improved by removing the solvent slowly which is achieved by increasing the pressure inside the system of spin-coating during the film growth.
\end{abstract}

\section{Introduction}

Currently, silicon and inorganic thin films solar cells technologies dominate the photovoltaic (PV) market [1]. However, partially due to the high production cost and related environmental issues, conventional PV technology must be replaced by emerging technologies such as organic-based PV (OPV) or hybrid solar cells. Organic semiconductors show great promise owing to their synthetic variability, lowtemperature processing, and the possibility of producing lightweight, flexible, easily manufactured, and inexpensive solar cells [2-4].

Great progress has been made in increasing the power conversion efficiency (PCE) of solution processed devices during the last ten years. In OPV, in 2001, Shaheen et al. [5] reported a record efficiency of $2.5 \%$ and about 10 years later
PCE $>10 \%$ has been demonstrated for lab devices [6]. On the other hand, perovskite solar cells emerged around 2012 with efficiencies of 9\% [7] and nowadays those PCE have been increased to more than 20\% [6]. However, those efficiencies are too low for practical uses at present, so that the device efficiency must be increased by improving processing conditions [8], postfabrication treatments [9], or the use of new advanced materials with new device designs $[10,11]$. P3HT is a widely studied material for OPV manufacture mixed with PCBM (phenyl-C61-butyric acid methyl ester) [12] and a promising hole transport material in emerging perovskite based solar cells devices [13]. Chlorobenzene is the most used solvent to date for deposition by spin-coating of $\mathrm{P} 3 \mathrm{HT}$ and P3HT:PCBM films used in organic solar cells [14]. However, using new solvents is a recognized approach to improve the properties of the solution processing-deposited materials. 
The performance of OPV devices is strongly influenced by the electrical transport properties, especially by the charge carrier mobility of the organic materials, which depends on many factors related to the processing of the organic layers, including the molecular packing and disorder [15]. The mobility of organic-based thin films has been evaluated by different techniques such as time of flight (TOF) [16], charge extraction by a linear increased voltage (CELIV) [17], field effect transistor configuration (FTC) [18], and impedance spectroscopy [19]. Mobility values ranging from $10^{-8}$ to $10^{-1} \mathrm{~cm}^{2} / \mathrm{V}$ s have been reported for P3HT and P3HT:PCBM blend, depending on the processing and molecular ordering of the sample [16, 20-22]. Impedance spectroscopy is a versatile technique useful to study the electrical transport and charge accumulation in materials as well as the recombination rates and Schottky barriers on the interfaces of devices. The mentioned phenomena are generally evaluated by solving the equivalent electrical circuits that model the experimental impedance spectra and correlating the elements of the equivalent circuit with the electrical properties of the studied device [23].

In this work, devices with structure ITO/active layer/M, where the active layers are P3HT, PCBM, and P3HT:PCBM, as well as devices with structure ITO/HTL/active layer/M, where, as HTL (hole transport layer), PEDOT:PSS and s$\mathrm{CuPC}$ are used, were evaluated through impedance spectroscopy measurements. The mobility changes in the active layers by using a conventional solvent (chlorobenzene) and a new solvent (mesitylene) were evaluated, and also the effect of the solvent evaporation rate during the spin-coating deposition of the active layer and the use of hole transport layer on mobility were studied. Additionally, a study of the effect on the mobility of the P3HT films when these are exposed to air was realized.

\section{Material and Methods}

P3HT, PCBM, and P3HT:PCBM films were prepared by spincoating from precursor solutions at $1 \% \mathrm{w} / \mathrm{w}$ stirred at $60^{\circ} \mathrm{C}$ during a period of 12 hours in organic solvents; samples with thicknesses varying between 50 and $200 \mathrm{~nm}$ were deposited for different experiments, using a WS-400BZ-GNPP/LITE spin-coating system operated under an optimized routine. For samples prepared from mesitylene based solutions, it was necessary to heat the precursor solution prior to the deposition to achieve good film homogeneity. PEDOT:PSS and CuPC films with thicknesses varying between 15 and $45 \mathrm{~nm}$ were also deposited by spin-coating from aqueous precursor solutions at $1 \% \mathrm{w} / \mathrm{w}$ and $5 \mathrm{mM}$, respectively. Commercial indium tin oxide (ITO) coated substrates were used as bottom electric contact and thin films of $\mathrm{Ag}$ and $\mathrm{Al}$ evaporated in high vacuum ambience on $\mathrm{P} 3 \mathrm{HT}$ layers were used as top contacts. As the commercial systems of spin-coating do not include facilities to deposit thin films under controlled pressure, the samples prepared by varying the pressure inside the spincoating system were grown in a modified system designed and implemented in our laboratory which allows depositing thin films in prevacuum ambience and under pressures of nitrogen higher than the room pressure, controlled through

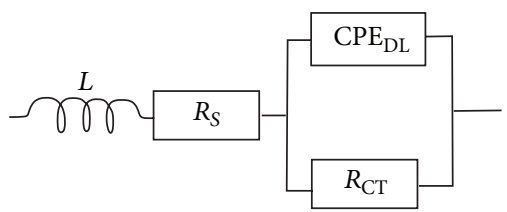

FIGURE 1: Equivalent circuit used to fit the impedance response.

an electronic flow mass controller. The growth of thin films controlling the partial pressure inside the system of spincoating is carried out in order to vary the speed at which the solvent evaporates.

The equivalent circuit model proposed to fit the experimental impedance spectra is shown in Figure 1. $L$ accounts for the inductive noise that results from electromagnetic radiation interferences evidenced by the negative values of imaginary impedance at high frequencies and $R_{s}$ takes into account the resistance of electrical contacts. The bulk-heterojunction concept implies a mixture of donor and acceptor materials, so that the active layer can be seen as a virtual semiconductor, where electrons and holes move through the acceptor and donor transport channels, respectively [24]. In that case, the system ITO/P3HT:PCBM/Al(Ag) behaves as a metalinsulator-metal (MIM) system whose equivalent circuit consists of a parallel resistor-capacitor arrangement; here, the constant phase element (CPE) replaces the ideal capacitor associated with charge carrier accumulation in the depletion layer (DL) near the metal-semiconductor interface [25] and $R_{\mathrm{CT}}$ is the resistance associated with charge transfer through the device. For the simulation of impedance spectra obtained from devices with ITO/HTL/P3HT/Ag structure, the same equivalent circuit was used assuming that the incorporation of the HTL layer affects mainly the value of $R_{s}$.

The impedance associated with the circuit of Figure 1 is given by

$$
Z=R_{s}+\frac{R_{\mathrm{CT}}}{1+\tau_{\mathrm{CT}}^{2} \omega^{2}}-i \frac{R_{\mathrm{CT}} \tau_{\mathrm{CT}} \omega}{1+\tau_{\mathrm{CT}}^{2} \omega^{2}}+i \omega L,
$$

where $\omega$ is the angular frequency and $\tau_{\mathrm{CT}}$ is the charge transfer time. It was found that the fitted data obtained using this equivalent circuit model match the experimental impedance spectra, with an average error less than $2 \%$.

In this work, special emphasis was placed on studying the influence of both solvent type and rate at which the solvent is removed from the samples on the carriers mobility of P3HT and P3HT:PCBM blends. The mobility was estimated using (2), derived from the equation of Einstein that relates the diffusion coefficient with the mobility and from the NernstEinstein equation that relates the diffusion coefficient with the charge transfer time $\tau_{\mathrm{CT}}$ [26], this latter defined as the change of charge carriers concentration near the interface, relative to the change in the charge transfer rate [27]. Hence,

$$
\mu=\frac{e L^{2}}{k_{b} T R_{\mathrm{CT}} C_{\mathrm{DL}}},
$$

where $L$ is the width of the depletion zone that is approximately equal to the film thickness as the films studied are very 
resistive and thin enough, $k_{b}$ is the Boltzmann constant, and $T$ is the temperature. $C_{\mathrm{DL}}$ and $R_{\mathrm{CT}}$ were estimated by fitting the Nyquist experimental curves (obtained for devices with structures ITO/P3HT/Ag and ITO/P3HT:PCBM/Ag), with curves theoretically simulated using the software "EIS spectrum analyzer" for the equivalent circuit shown in Figure 1.

\section{Results and Discussion}

3.1. Results. Initially, the use of $\mathrm{Ag}$ and $\mathrm{Al}$ films as cathode of devices with structures ITO/P3HT/Al(Ag) and ITO/PCBM/ $\mathrm{Al}(\mathrm{Ag})$ was evaluated through IS spectroscopy measurements. These results revealed that the resistance $R_{\mathrm{CT}}$ associated with charge transfer through the device ITO/P3HT/Al is three orders of magnitude greater than the one obtained for the device ITO/P3HT/Ag, indicating that $\mathrm{Al}$ acts as Schottky barrier for majority carriers (holes) and Ag acts as ohmic contact for minority carriers (electrons). On the contrary, the results revealed that $R_{\mathrm{CT}}$ associated with charge transfer through the device ITO/PCBM/Al is significantly less than that of the ITO/PCBM/Ag device indicating that in this case $\mathrm{Al}$ acts as ohmic contact for electrons generated in the PCBM film.

\subsubsection{Effect of Solvent Evaporation Rate and Solvent Type.} Since in a study previously performed within our group we found that the optical and structural properties of thin films of P3HT:PCBM prepared by spin-coating can be improved by controlling the speed at which the solvent is removed during deposition [28], we decided to study the influence of the speed at which the solvent evaporates during the deposition on the electrical properties of thin films of P3HT:PCBM blends. The solvent evaporation rate is controlled by controlling the pressure inside the deposition chamber during deposition. Deposition under higher pressures leads to a decrease in the evaporation rate of the solvent due to an increase in the system pressure with respect to the solvent vapor pressure; on the contrary, the solvent evaporation rate increases when the deposition is made under prevacuum conditions due to the fact that in this case the difference between system pressure and solvent vapor pressure decreases.

Figure 2 displays experimental Nyquist curves of ITO/P3HT:PCBM/Al systems measured at $0.3 \mathrm{~V}$ of reverse bias using P3HT:PCBM films deposited from chlorobenzene based solutions keeping the spin-coating system under different pressures $(146,746$, and 3746 mbar, resp.). It can be seen from the size of semicircles of Figure 2 that the highest value of $R_{\mathrm{CT}}$ corresponds to the sample prepared at $146 \mathrm{mbar}$ and the lowest value corresponds to the sample prepared at $3746 \mathrm{mbar}$ indicating that the charge transport is faster in the sample deposited at higher pressure. In addition, Figure 2 shows that the total resistance of devices with ITO/P3HT:PCBM/Al structures decreases by increasing the pressure at which the P3HT:PCBM film is grown.

The mobility $\mu$ of the charge carriers and the mobility normalized with respect to $\mathrm{CPE}_{\mathrm{DL}}$, in function of the pressure inside the spin-coater during the layer deposition, are shown in Table 1.

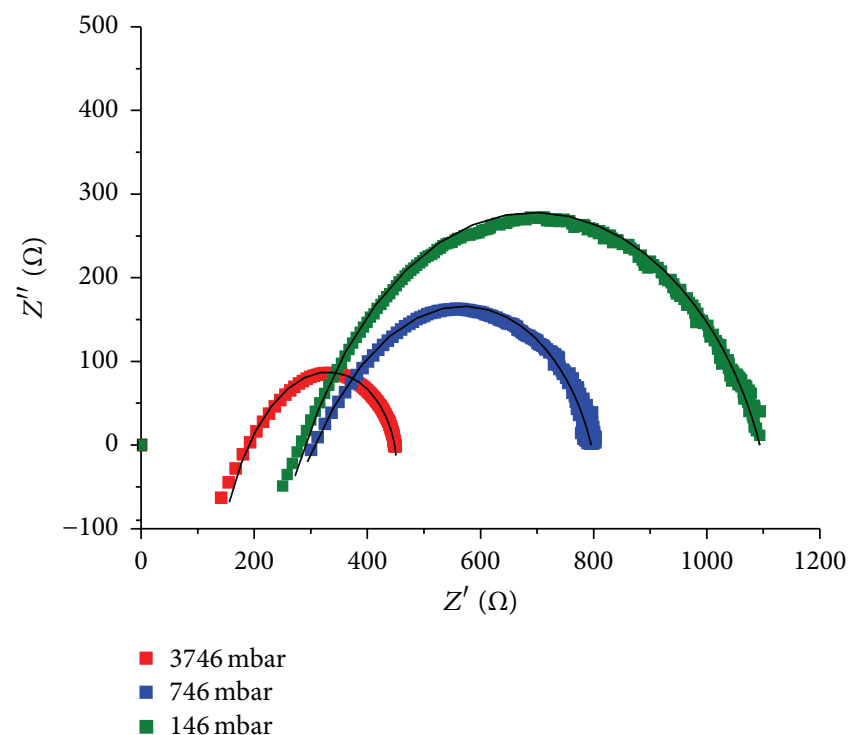

Figure 2: Experimental Nyquist curves obtained for devices with ITO/P3HT:PCBM/Al structure, with the P3HT:PCBM blend prepared from a precursor solution based on chlorobenzene, spincoated at different pressures. Symbol curves represent experimental data and solid curves represent the theoretical fit.

TABLE 1: Values of mobility estimated from IS measurements carried out on ITO/P3HT:PCBM/Al structures applying a $0.3 \mathrm{~V}$ reverse bias, with P3HT:PCBM films prepared at different pressures using chlorobenzene as solvent.

\begin{tabular}{lcc}
\hline Pressure & $\mu\left(\mathrm{cm}^{2} / \mathrm{Vs}\right)$ & $\mu / C_{\mathrm{DL}}\left(\mathrm{cm}^{2} / \mathrm{VsF}\right)$ \\
\hline $146 \mathrm{mbar}$ & $1.8 \times 10^{-4}$ & $3.0 \times 10^{4}$ \\
$746 \mathrm{mbar}$ & $3.8 \times 10^{-4}$ & $1.1 \times 10^{5}$ \\
$3746 \mathrm{mbar}$ & $2.5 \times 10^{-3}$ & $2.5 \times 10^{6}$ \\
\hline
\end{tabular}

TABLE 2: Mobility values of majority and minority carriers in P3HT films prepared from chlorobenzene and mesitylene based solutions.

\begin{tabular}{lcc}
\hline Solvent & $\mu_{p}\left(\mathrm{~cm}^{2} / \mathrm{Vs}\right)$ & $\mu_{n}\left(\mathrm{~cm}^{2} / \mathrm{Vs}\right)$ \\
\hline Chlorobenzene & $\left(2,9 \times 10^{-7}\right)$ & $\left(2.1 \times 10^{-3}\right)$ \\
Mesitylene & $\left(6.0 \times 10^{-6}\right)$ & $\left(3,6 \times 10^{-3}\right)$ \\
\hline
\end{tabular}

A common way to improve the properties of spin-coated layers is through the use of an adequate solvent. Based on previous results that showed improved optical and structural properties of $\mathrm{P} 3 \mathrm{HT}$ films prepared using mesitylene, which is as a novel solvent [28], we studied the influence of solvent type on the mobility of minority $\left(\mu_{n}\right)$ and majority $\left(\mu_{p}\right)$ carriers in $\mathrm{P} 3 \mathrm{HT}$ thin films by IS measurements using ITO/P3HT/ $\mathrm{Ag}$ and ITO/P3HT/Al structures, respectively. In Table 2, values of mobility obtained for both majority and minority carriers in P3HT films prepared from both chlorobenzene and mesitylene based solutions are listed.

3.1.2. Influence of the HTL Layer. The influence of the HTL layer on the carriers mobility of P3HT, PCBM, and P3HT:PCBM blends deposited by spin-coating from a 
TABLE 3: Mobility of holes (in P3HT films) and electrons (in PCBM films) and mean mobility of carriers in the P3HT:PCBM blends, estimated from impedance measurements using ITO/HTL/active layer/Al structures.

\begin{tabular}{lccc}
\hline HTL/active layer & $\begin{array}{c}\mu\left(\mathrm{cm}^{2} / \mathrm{Vs}\right) \\
\text { P3HT:PCBM }\end{array}$ & $\begin{array}{c}\mu_{p}\left(\mathrm{~cm}^{2} / \mathrm{Vs}\right) \\
\text { P3HT }\end{array}$ & $\begin{array}{c}\mu_{n}\left(\mathrm{~cm}^{2} / \mathrm{Vs}\right) \\
\text { PCBM }\end{array}$ \\
\hline PEDOT:PSS & $6.5 \times 10^{-5}$ & $3.6 \times 10^{-5}$ & $1.0 \times 10^{-7}$ \\
CuPC & $3.4 \times 10^{-6}$ & $2.6 \times 10^{-7}$ & $2.3 \times 10^{-3}$ \\
\hline
\end{tabular}

TABLE 4: Mean mobility $\mu$ of carriers in P3HT:PCBM blends prepared using chlorobenzene and mesitylene based solutions; $\mu$ calculated from IS measurements performed using ITO/HTL/P3HT:PCBM/Al device structures.

\begin{tabular}{lcc}
\hline HTL/solvent & $\begin{array}{c}\mu\left(\mathrm{cm}^{2} / \mathrm{Vs}\right) \\
\text { Mesitylene }\end{array}$ & $\begin{array}{c}\mu\left(\mathrm{cm}^{2} / \mathrm{Vs}\right) \\
\text { Chlorobenzene }\end{array}$ \\
\hline PEDOT:PSS & $6.5 \times 10^{-5}$ & $1.3 \times 10^{-7}$ \\
CuPC & $3.4 \times 10^{-6}$ & $2.8 \times 10^{-3}$ \\
\hline
\end{tabular}

mesitylene based solution was studied through IS measurements performed on ITO/HTL/active layer/Al device structures, where HTL is either PEDOT:PSS or s-CuPC and "active layer" corresponds to thin films of P3HT, PCBM, or P3HT:PCBM blends. In Figure 3, the corresponding Nyquist curves are plotted.

The mobility of majority carriers in P3HT and PCBM films (holes in P3HT and electrons in PCBM) and the mean mobility of carriers in the P3HT:PCBM blend were determined using (2) and values of $C_{\mathrm{DL}}$ and $R_{\mathrm{CT}}$ estimated by fitting the Nyquist curves shown in Figure 3. In Table 3, the IS measurements carried out on devices with ITO/HTL/ $\mathrm{PCBM} / \mathrm{Al}$ structure revealed that the electron mobility is much higher using CuPC as HTL layer instead of using PEDOT:PSS, indicating that hole transference between active layer and anode is more difficult when PEDOT:PSS is used. In devices with ITO/HTL/P3HT/Al structure, PEDOT:PSS favors hole transport opposite to CuPC layer. As can be seen in Table 3, similar results are observed when P3HT:PCBM blends are used as active layer.

In Table 3, values of mobility obtained for electrons in $\operatorname{PCBM}\left(\mu_{n}\right)$ and for hole in P3HT $\left(\mu_{p}\right)$ and the mean mobility $\mu$ obtained for the P3HT:PCBM blend are listed.

The IS measurements carried out on devices with ITO/ HTL/PCBM/Al structure revealed that the electron mobility is much higher using CuPC as HTL layer instead of using PEDOT:PSS, indicating that hole transference between active layer and anode is more difficult when PEDOT:PSS is used. In devices with ITO/HTL/P3HT/Al structure, PEDOT:PSS favors hole transport opposite to CuPC layer. As can be seen in Table 3, similar results are observed when P3HT:PCBM blends are used as active layer.

The mean mobility $\mu$ of carrier in the P3HT:PCBM blends prepared from precursor solutions based on both chlorobenzene and mesitylene was estimated by fitting the Nyquist curves obtained from IS measurements carried out using devices with ITO/HTL/P3HT:PCBM/Al structures, where PEDOT:PSS and s-CuPC are used as HTL layer. In Table 4, the corresponding values of carriers mean mobility $\mu$ in P3HT:PCBM blends are listed. These results reveal that PEDOT:PSS blocks the carrier transport when chlorobenzene is used for the preparation of the P3HT:PCBM blend; on the contrary, the carrier transport is enhanced when mesitylene is used for the preparation of the P3HT:PCBM blend. The results also reveal that, using s-CuPC as HTL layer, the transport of carriers is improved when chlorobenzene is used for the preparation of the P3HT:PCBM blend.

\subsubsection{Effect of Exposure to Air on the Mobility of the P3HT} Films. A study of the effect of exposure of P3HT films to the air at room luminosity conditions on the carrier mobility was carried out using ITO/P3HT/Ag device structures. Figure 4 shows the influence that the exposure to air produces on the mobility of P3HT films. It is observed that, during the first hours of exposition, the carriers mobility decreases very fast and then the decrease is quite slow. This result indicates that it is necessary to encapsulate the final organic device and that the organic material synthesis must be done under vacuum and inert conditions to prevent the degradation of its electrical properties.

The effect of exposition time of P3HT to the air on the concentration of the acceptor impurities $N_{A}$ and on built-in potential $V_{0}$ was also studied using the Mott-Schottky relation [27]:

$$
C_{\mathrm{SC}}^{-2}=\frac{1\left(V_{0}-V\right)}{A^{2} e \varepsilon \varepsilon_{0} N_{A}},
$$

where $\varepsilon$ is the static permittivity of $\mathrm{P} 3 \mathrm{HT}, \varepsilon_{0}$ is the vacuum permittivity, and $A$ is the device area.

Figure 5 shows plots of inverse of square capacitance associated with the space charge accumulated close to the $\mathrm{Ag} / \mathrm{P} 3 \mathrm{HT}$ interface $\left(C_{\mathrm{SC}}\right)$ as a function of DC potential, where the capacitance $C_{\mathrm{SC}}$ was determined from IS measurements performed immediately after the deposition of the ITO/ $\mathrm{P} 3 \mathrm{HT} / \mathrm{Ag}$ structure and after 32 hours of exposition to air, respectively. The linear behavior of the graphs is in accordance with interface type Mott-Schottky [27]. The acceptor concentration $N_{A}$ was calculated from the slope of the curves of $1 / C_{\mathrm{SC}}^{2}$ versus $V_{\mathrm{DC}}$ and the built-in potential $V_{0}$ was calculated from the intercept with the $y$-axis. It was found that the P3HT films exhibit an acceptor concentration $N_{A}$ of 3,4 $\times 10^{16} \mathrm{~cm}^{-3}$ immediately after the deposition, which is very close to that reported for devices encapsulated with epoxy resins $\left(3,5 \times 10^{16} \mathrm{~cm}^{-3}\right)$ [29]. A value of $N_{A}=7,7 \times 10^{15} \mathrm{~cm}^{-3}$ was obtained for $\mathrm{P} 3 \mathrm{HT}$ films exposed to air during a period of 32 hours. These results indicate that the exposure to air of the P3HT film leads to a decrease of both carriers concentration and carriers mobility.

As is observed from Figure 5, the built-in potentials $V_{0}$ measured immediately after the deposition of the P3HT films and after 32 hours of exposition to air are $0.7 \mathrm{~V}$ and $0.6 \mathrm{~V}$, respectively, which are very close to the theoretical expected value of $0.6 \mathrm{~V}$ [30].

3.2. Discussion of Results. It is clear from data of Table 1 that the samples dried slowly during deposition under pressures 

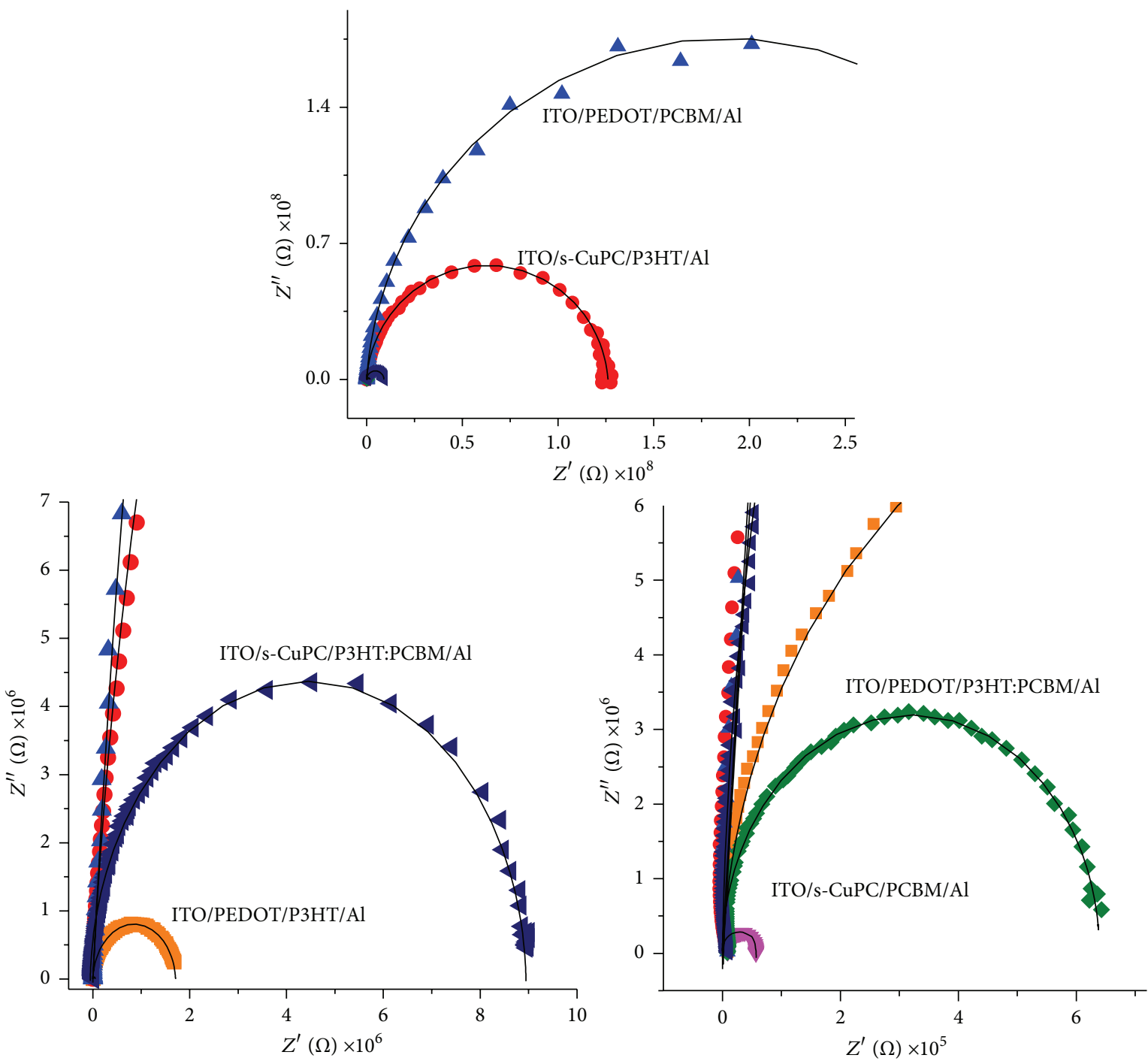

FIGURE 3: Nyquist curves obtained from IS measurements performed on nine different ITO/HTL/active layer/Al structures. Symbol curves represent experimental data and solid curves represent the theoretical fit.

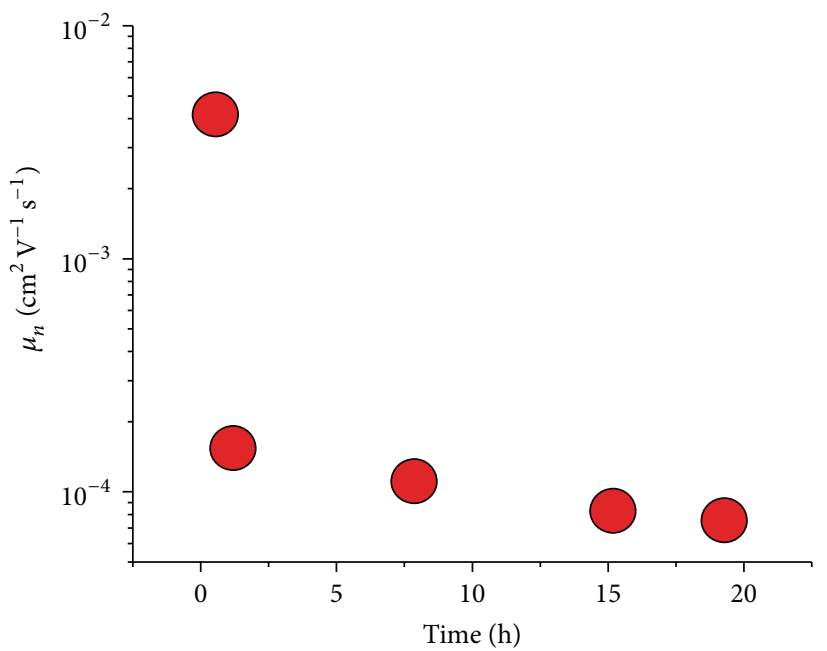

Figure 4: Variation of the carriers mobility in P3HT films as a function of exposure time to the air. 


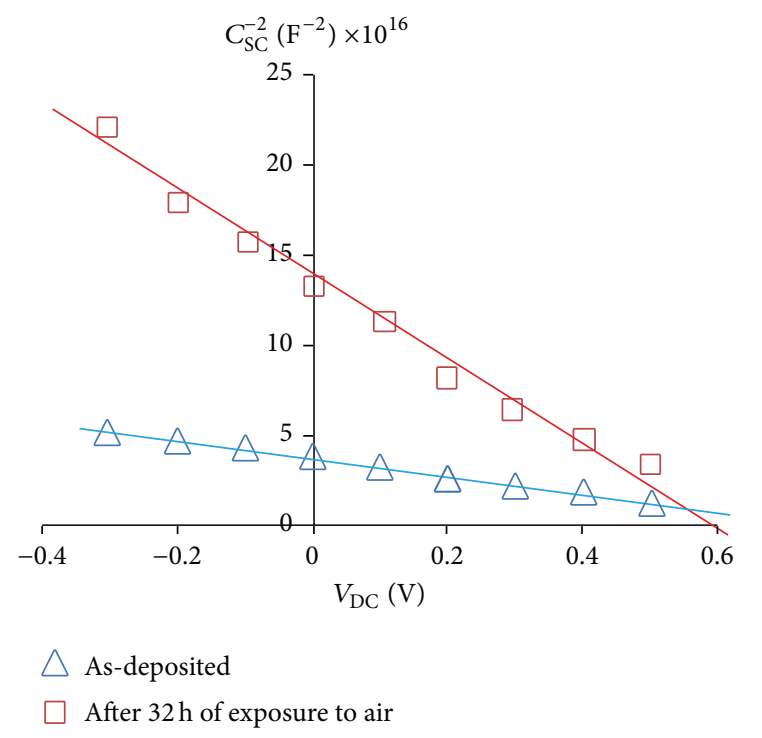

FIGURE 5: Mott-Schottky curves $\left(C_{\mathrm{SC}}^{-2}\right.$ versus $\left.V_{\mathrm{DC}}\right)$ performed using $C_{\mathrm{SC}}$ values determined from impedance spectra measured immediately after the deposition of the ITO/P3HT/Ag structure and after 32 hours of exposition to the air, respectively.

greater than atmospheric pressure exhibit higher mobility, apparently due to an improved degree of crystallinity as a consequence of improved ordering of the P3HT chains as it has been proposed in previous studies [28]. The results obtained in this work allow us to confirm that the proposed methodology to improve the properties of thin films prepared by controlling the pressure during the spin-coating deposition is really effective.

Considering the results of Table 2 which show that the highest values of mobility of both majority and minority carriers correspond to P3HT films prepared using mesitylene as a solvent, it can be concluded that this type of solvent leads to the best electrical properties compared with those of samples prepared using conventional solvents as chlorobenzene. It is worth mentioning that previous studies we have made revealed that the optical and structural properties of P3HT films prepared using mesitylene are significantly better than those of P3HT films prepared using chlorobenzene as a solvent [28].

In accordance with the results of Table 3 , it can be seen that the PEDOT:PSS is more suitable as hole transport and blocking electrons layer in comparison with the CuPC.

The results listed in Table 4 show that the mobility of devices is in general greater when the active layer is prepared using mesitylene as a solvent; however, the mobility in devices with structure ITO/CuPC/P3HT:PCBM (chlorobenzene)/Al is the highest. This behavior can be explained assuming formation of $\mathrm{CuPC} / \mathrm{PCBM}$ interfaces (donor-acceptor) [31] since chlorobenzene favors homogeneous distribution of $\mathrm{P} 3 \mathrm{HT}$ and PCBM along the active layer. This phenomenon does not occur when mesitylene is used, because the difference of the solubility of P3HT with respect to that of the PCBM induces phase separation of the materials, leading to higher concentration of P3HT near ITO.
The degradation of the mobility of the P3HT films when they are exposed to the air (see Figure 4) seems to be a consequence of the breaking of the polymer chain conjugation, due to the incorporation of oxygenated species [32]. As the effective conjugation length diminishes, the electrical transport associated with delocalization vanishes and transport associated with quantum hopping becomes more important.

\section{Conclusions}

The electrical transport properties of materials used as HTL and as active layer in organic solar cells were studied using the technique of impedance spectroscopy and the results were analyzed by fitting experimental Nyquist curves with curves theoretically simulated using the software "EIS spectrum analyzer" for an equivalent circuit proposed for bulk-heterojunction type device structures.

It was found that thin films of P3HT and P3HT:PCBM blends prepared using a precursor solution based on mesitylene present significantly better electrical transport properties than those prepared from a precursor solution based on chlorobenzene. The impedance spectroscopy studies also revealed that the electrical properties of P3HT:PCBM films can be improved by controlling the solvent evaporation rate by controlling the pressure inside the spin-coating system during the deposition. In general, the carrier mobility in the P3HT:PCBM blend is significantly improved, increasing the pressure inside the spin-coating system. We also found that when the $\mathrm{P} 3 \mathrm{HT}$ is exposed to the air, both the mobility of carriers and the concentration of impurities decrease markedly. The studies realized also allowed confirming that $\mathrm{P} 3 \mathrm{HT}$ forms a Schottky barrier with $\mathrm{Al}$ and ohmic contact with ITO and $\mathrm{Ag}$, while PCBM forms ohmic contact with Al. In addition, we were able to prove that P3HT:PCBM forms ohmic contact with $\mathrm{Al}$. On the other hand, we found evidence that PEDOT:PSS blocks the electron transport towards the anode while s-CuPC favors the electron transport.

\section{Competing Interests}

The authors declare that they have no competing interests.

\section{References}

[1] M. A. Green, K. Emery, Y. Hishikawa, W. Warta, and E. D. Dunlop, "Solar cell efficiency tables (version 46)," Progress in Photovoltaics: Research and Applications, vol. 23, no. 7, pp. 805-812, 2015.

[2] H. Cao, W. He, Y. Mao et al., "Recent progress in degradation and stabilization of organic solar cells," Journal of Power Sources, vol. 264, pp. 168-183, 2014.

[3] I. Etxebarria, J. Ajuria, and R. Pacios, "Solution-processable polymeric solar cells: a review on materials, strategies and cell architectures to overcome 10\%," Organic Electronics, vol. 19, pp. 34-60, 2015.

[4] S. S. Sun, J. Brooks, T. Nguyen, A. Harding, D. Wang, and T. David, "Novel organic and polymeric materials for solar energy conversions," Energy Procedia, vol. 57, pp. 79-88, 2014. 
[5] S. E. Shaheen, C. J. Brabec, N. S. Sariciftci, F. Padinger, T. Fromherz, and J. C. Hummelen, "2.5\% efficient organic plastic solar cells," Applied Physics Letters, vol. 78, no. 6, pp. 841-843, 2001.

[6] “NREL efficiency chart," June 2015, http://www.nrel.gov/ncpv/ images/efficiency_chart.jpg.

[7] H.-S. Kim, C.-R. Lee, J.-H. Im et al., "Lead iodide perovskite sensitized all-solid-state submicron thin film mesoscopic solar cell with efficiency exceeding 9\%," Scientific Reports, vol. 2, article 591, 2012.

[8] Q. Wu, Improved efficiency organic photovoltaic cells through morphology control and process modification [Ph.D. dissertations], University of Southern Mississippi, 2014.

[9] S. M. Abdullah, Z. Ahmad, and K. Sulaiman, "The impact of thermal annealing to the efficiency and stability of organic solar cells based on PCDTBT: PC $_{71}$ BM," Procedia-Social and Behavioral Sciences, vol. 195, pp. 2135-2142, 2015.

[10] S. Albrecht, S. Yilmaz, I. Dumsch et al., "Solution processed organic tandem solar cells," Energy Procedia, vol. 31, pp. 159-166, 2012.

[11] X. Liu, H. Chen, and S. Tan, "Overview of high-efficiency organic photovoltaic materials and devices," Renewable and Sustainable Energy Reviews, vol. 52, pp. 1527-1538, 2015.

[12] Y. Zhang, T. P. Basel, B. R. Gautam et al., "Spin-enhanced organic bulk heterojunction photovoltaic solar cells," Nature Communications, vol. 3, article 1043, 2012.

[13] Y. Guo, C. Liu, K. Inoue, K. Harano, H. Tanaka, and E. Nakamura, "Enhancement in the efficiency of an organic-inorganic hybrid solar cell with a doped P3HT hole-transporting layer on a void-free perovskite active layer," Journal of Materials Chemistry A, vol. 2, no. 34, pp. 13827-13830, 2014.

[14] Y. Xie, P. Dutta, D. Cengher et al., "Solvent effect on the morphology of P3HT/PCBM films," in Proceedings of SPIE, vol. 7416, pp. 74161Q-1-74161Q-8.

[15] Y. Shen, Investigation of Electrical Properties of P3HT:PCPBM Organic Solar Cells, University of Virginia, Charlottesville, Va, USA, 2013.

[16] K. Yang, Y. Wang, A. Jain, L. Samulson, and J. Kumar, "Determination of electron and hole mobility of regioregular poly(3hexylthiophene) by the time of flight method," Journal of Macromolecular Science, Part A: Pure and Applied Chemistry, vol. 44, no. 12, pp. 1261-1264, 2007.

[17] A. Kokil, K. Yang, and J. Kumar, "Techniques for characterization of charge carrier mobility in organic semiconductors," Journal of Polymer Science Part B: Polymer Physics, vol. 50, no. 15, pp. 1130-1144, 2012.

[18] G. Juška, N. Nekrašas, K. Genevičius, and T. Grigaitis, “The determination of charge carrier mobility from the current transients in organic field effect transistor," Journal of Applied Physics, vol. 116, no. 2, Article ID 023702, 2014.

[19] P. Pingel, R. Schwarzl, and D. Neher, "Effect of molecular p-doping on hole density and mobility in poly(3-hexylthiophene)," Applied Physics Letters, vol. 100, no. 14, Article ID 143303, 2012.

[20] E. von Hauff, V. Dyakonov, and J. Parisi, "Study of field effect mobility in PCBM films and P3HT:PCBM blends," Solar Energy Materials \& Solar Cells, vol. 87, no. 1-4, pp. 149-156, 2005.

[21] H. Sirringhaus, N. Tessler, and R. H. Friend, "Integrated optoelectronic devices based on conjugated polymers," Science, vol. 280, no. 5370, pp. 1741-1744, 1998.
[22] F. Laquai, D. Andrienko, R. Mauer, and P. W. M. Blom, “Charge carrier transport and photogeneration in P3HT:PCBM photovoltaic blends," Macromolecular Rapid Communications, vol. 36, no. 11, pp. 1001-1025, 2015.

[23] E. Barsoukov and J. R. Macdonald, Impedance Spectroscopy Theory, Experiment, and Applications, Wiley-Interscience, New Jersey, NJ, USA, 2nd edition, 2005.

[24] A. Gaur and P. Kumar, "An improved circuit model for polymer solar cells," Progress in Photovoltaics: Research and Applications, vol. 22, no. 9, pp. 937-948, 2014.

[25] M. E. Orazem and B. Tribollet, Electrochemical Impedance Spectroscopy, John Wiley \& Sons, Hoboken, NJ, USA, 2008.

[26] B. Streetman and S. Kumar, Solid State Electronic Devices, PHI Learning, 2009.

[27] J. Bisquert and F. Fabreagat-Santiago, Impedance Spectroscopy: A General Introduction and Application to Dye-Sensitized Solar Cells, chapter 12, Taylor \& Francis, Boca Raton, Fla, USA, 2010.

[28] C. A. Otálora, A. F. Loaiza, and G. Gordillo, "Influence of solvent on the molecular ordering of thin films of P3HT:PCBM blends and precursor solution," in Proceedings of the 40th IEEE Photovoltaic Specialist Conference (PVSC '14), pp. 1754-1757, Denver, Colo, USA, June 2014.

[29] G. G. Belmonte, A. Munar, E. M. Barea, J. Bisquert, I. Ugarte, and R. Pacios, "Charge carrier mobility and lifetime of organic bulk heterojunctions analyzed by impedance spectroscopy," Organic Electronics, vol. 9, no. 5, pp. 847-851, 2008.

[30] Z. Xu, L.-M. Chen, M.-H. Chen, G. Li, and Y. Yang, "Energy level alignment of poly(3-hexylthiophene): [6,6]-phenyl C 61 butyric acid methyl ester bulk heterojunction," Applied Physics Letters, vol. 95, no. 1, Article ID 013301, 2009.

[31] A. H. Ahmad Makinudin, M. S. Fakir, and A. Supangat, "Metal phthalocyanine: fullerene composite nanotubes via templating method for enhanced properties," Nanoscale Research Letters, vol. 10, article 53, pp. 1-8, 2015.

[32] A. Guerrero, P. P. Boix, L. F. Marchesi, T. Ripolles-Sanchis, E. C. Pereira, and G. Garcia-Belmonte, "Oxygen doping-induced photogeneration loss in P3HT:PCBM solar cells," Solar Energy Materials and Solar Cells, vol. 100, pp. 185-191, 2012. 

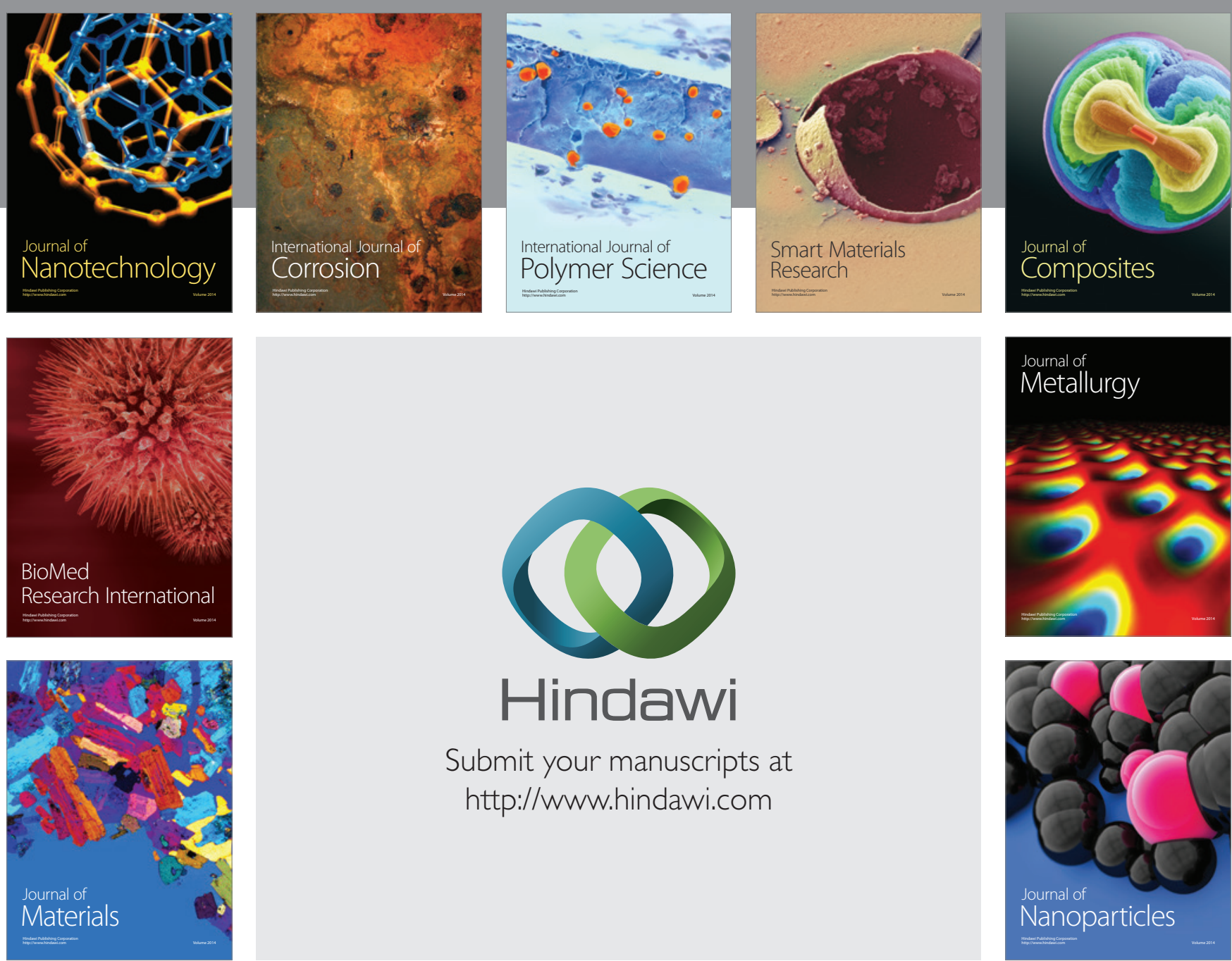

\section{Hindawi}

Submit your manuscripts at

http://www.hindawi.com

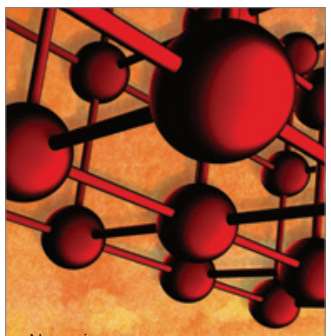

Materials Science and Engineering
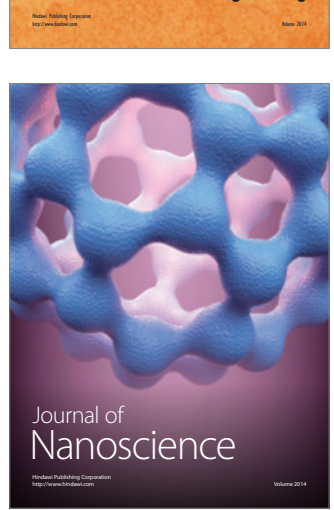
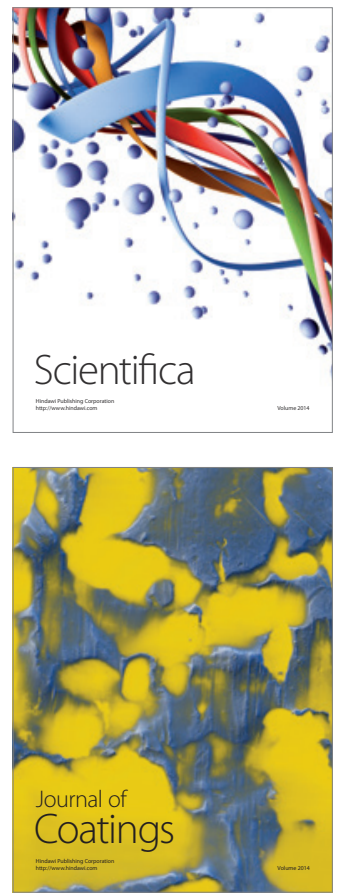
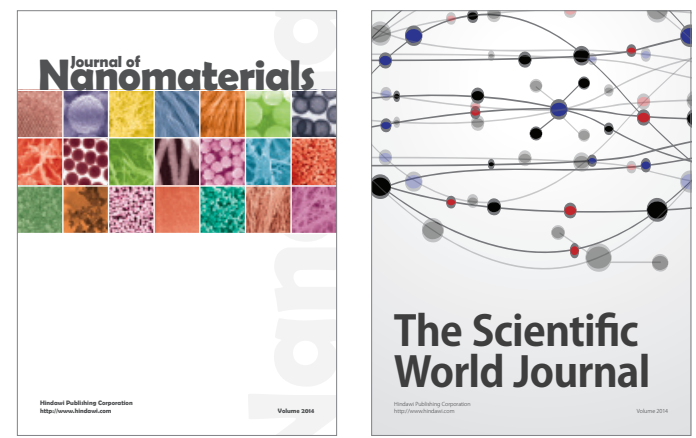

The Scientific World Journal
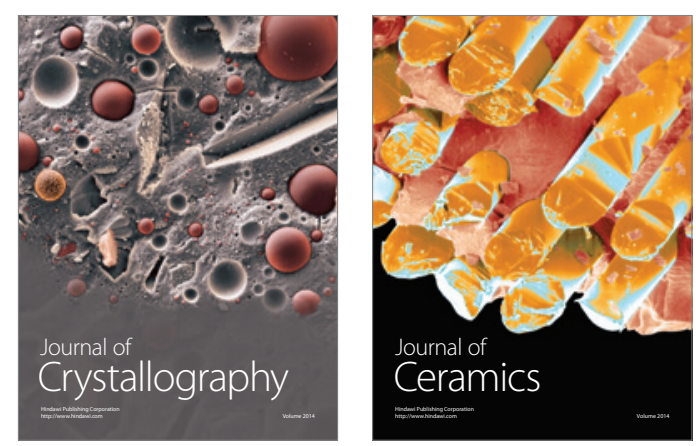
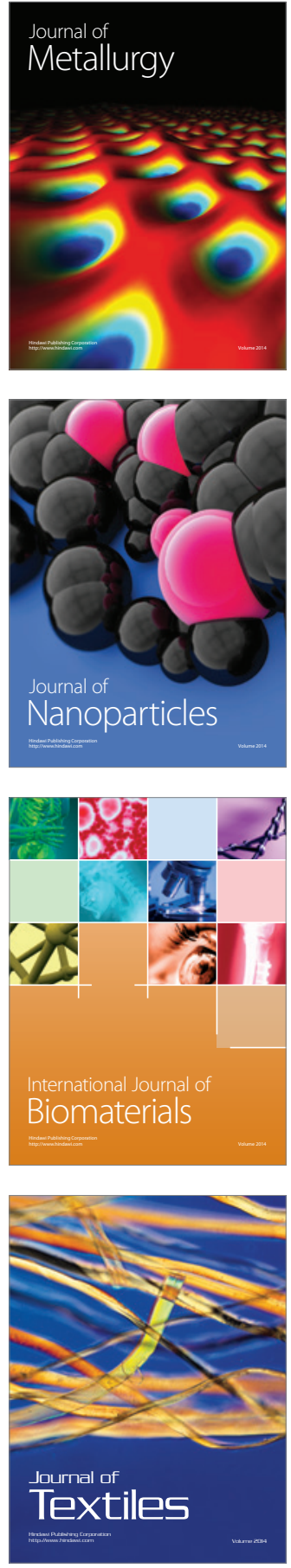